Rubric 2. SCIENTIFIC AND PRACTICAL DEVELOPMENTS

Field - Electrical Engineering

UDC 621.311.2

DOI 10.17816/transsyst202173131-149

\author{
(C) A. N. J. Almakki ${ }^{1}$, A. A. Mazalov ${ }^{1,2}$ \\ ${ }^{1}$ Kazan National Research Technical University named after A.N. Tupolev \\ (Kazan, Russia) \\ ${ }^{2}$ South Federal University \\ (Rostov-On-Don, Russia)
}

\title{
IMPROVED DFIG DFTC BY USING A FRACTIONAL-ORDER SUPER TWISTING ALGORITHMS IN WIND POWER APPLICATION
}

Background: The direct flux and torque control are a robust, simple, and alternative approach control formulation that does not require decomposition into symmetrical components; the direct flux and torque control schemes have been proved to be preponderant for doubly-fed induction generators due to the simple implementation.

Aim: This work presents the minimization of electromagnetic torque and rotor flux undulations of doubly-fed induction generators using fractional-order super twisting algorithms and modified space vector modulation techniques.

Methods: The main role of direct flux and torque control is to regulate and control the electromagnetic torque and rotor flux of doubly-fed induction generators for wind turbine systems. The direct flux and torque control is a traditional control algorithm and robust technique. Fractional-order super twisting algorithms are a new and proposed nonlinear controller; characterized by a robust controller and a simpler algorithm, which gives a good harmonic distortion of current compared to other methods.

Novelty: The A fractional-order super twisting algorithm is proposed. Proposed nonlinear controller construction is based on the traditional super twisting algorithm and fractional calculus to obtain a robust controller and reduces the electromagnetic torque and rotor flux undulations of doubly-fed induction generators. We use in our study a $1.5 \mathrm{MW}$ doubly-fed induction generator integrated into a single-rotor wind turbine system to minimizes the electromagnetic torque, stator current, rotor flux undulations. As shown in the results figures using fractional-order super twisting algorithms ameliorate effectiveness especially minimizes the electromagnetic torque and rotor flux, and minimizes harmonic distortion of stator current $(0.16 \%)$ compared to the traditional control scheme.

Results: As shown in the results figures using fractional-order super twisting algorithms ameliorate effectiveness especially minimizes the electromagnetic torque and rotor flux, and minimizes harmonic distortion of stator current $(0.16 \%)$ compared to the traditional control scheme.

Conclusion: The direct flux and torque control are a robust, simple, and alternative approach control formulation that does not require decomposition into symmetrical components; the direct flux and torque control schemes have been proved to be preponderant for doubly-fed induction generators due to the simple implementation.

Keywords: Fractional order super twisting algorithms, direct flux and torque control, proportional-integral, doubly-fed induction generator, modified space vector modulation. 


\section{INTRODUCTION}

Due to the increasing demand for electrical energy, and the inability to meet this demand by using traditional sources. It led scientists and researchers to search for other sources in order to generate electric power at the lowest cost, as well as to reduce carbon dioxide emissions. Among the resources and solutions discovered, we find wind energy. The latter is inexpensive, renewable, and does not pollute the atmosphere. Among the leading countries in this field are China, the United States of American, Germany, France, Denmark, and India. China is the country in the world that ranks first in the world in the production of electric energy from wind energy, accounting for $27.4 \%$ of global production [1]. On the other hand, the generators most used in the field of electric power generation in the wind station are the asynchronous generator with a squirrel cage, the synchronous generator, asynchronous generator with a coiled rotor.

The doubly-fed induction generator (DFIG) is the most widely used and famous in the field of electric power generation, due to its characteristics compared to some generators. Among its characteristics, we find: ease to control, durability, and reduce the cost of producing electrical energy. There are several ways to control this generator, among them we find: backstepping control [2], synergetic control [3], direct flux and torque control [4], sliding mode control [5], direct power control [6] and field-oriented control [7].

Direct flux and torque control (DFTC) appeared in the mid-1980s as a method of controlling electrical machines aimed at controlling torque directly without using pulse width modulation [8]. The main objective of this method is to directly control the torque without using an internal loop, as well as to reduce the financial cost. This strategy is a simple algorithm, gives a good performance, fast dynamic response, and easy to apply compared to field-oriented control. in the traditional DFTC method, flux and electromagnetic torque can be directly controlled by using two hysteresis comparators and a switching table. In [9], the author applies the DFTC method to an asynchronous motor in order to improve performance and reduce ripples at both torque and flux levels. The synchronous motor was controlled using the DFTC method, where two hysteresis comparators were used to regulate the torque and flux of the synchronous motor [10]. The results showed the effectiveness of the proposed method. In [11], the author controlled the DFIG using the DFTC technique. The major drawback of DFTC, is the oscillations of the flux, the torque, and the harmonics of the currents generated by the DFIG, because of the variable switching frequencies. In [12], the DFTC method was proposed to control the flux and torque of the synchronous generator.

In recent years, several new methods have appeared in the field of artificial intelligence, for example neural networks, genetic algorithms, and fuzzy logic. These methods are simple and easy to implement and do not require a specialist. These methods provide very satisfactory results compared to the 
traditional methods. Several scientific works have improved the performance and effectiveness of DFTC control of the DFIG using artificial intelligence. In [13], the authors proposed the use of a DFTC method with fuzzy logic controllers applied to the DFIG-based wind turbines. In [14], the DFTC method based on neural networks has been proposed. The results showed the effectiveness of the proposed method. In [15], a modified DFTC method was proposed based on a genetic algorithm with a constant switching frequency, where a PI controller was calculated using a genetic algorithm. Fuzzy logic and neural networks are combined to improve the DFTC performance of DFIGbased wind turbines [16].

Similar to artificial intelligence, there are other methods to improve the performance and effectiveness of the DFTC technique under the name of nonlinear methods, and the results have shown their effectiveness in improving the performance and quality of results, especially in the case of changing machine parameters. Among the most popular nonlinear methods are sliding mode control, super twisting algorithm, synergetic control, fractional-order control, second-order sliding mode, second-order continuous sliding mode and backstepping control. In [17], an electromagnetic torque and rotor flux secondorder continuous sliding mode and space vector modulation (SVM) strategy were combined to replace the switching table and hysteresis comparators. Simulation results showed the robustness and effectiveness of the proposed method compared to the classical method. In [18], the author has improved the performance of DFTC control using super twisting algorithms (STAs). In this proposed method, STA controllers are used in place of hysteresis comparators and SVM technique in place of traditional switching table. Despite the results obtained from this method, the problem of ripples remains. Among the other proposed solutions is the integration of artificial intelligence with nonlinear methods in order to obtain more robust and effective methods than the classical nonlinear methods, and this is shown by the results of the work carried out in [19-21].

In this article, we propose a new nonlinear method in order to improve the performance and efficiency of DFTC control of the DFIG-based wind turbines. This proposed nonlinear method is based on STA and fractional calculations. Fractional order STA controllers (FOSTA) are the extension of the classical STA method with fractional calculus for better effectiveness of the drive. The proposed FOSTA controller is simple structure, easy to adjust, more robust algorithm, easy to apply, and improves dynamic response. On the other hand, it provides very satisfactory results compared to the classical methods.

In this work, we proposed a DFTC control, based on the SVM technique with different types of controllers (PI and FOSTA controllers), simple and hybrid in order to improve the quality of electrical energy supplied by the wind power system based on a DFIG. 
The objective of this work is to improve the performance of the DFTC control, applied to the DFIG integrated into the wind turbine system by the use of the control by FOSTA controllers.

A comparison between the numerical results obtained for the classical DFTC method with PI controllers and proposed DFTC validates the performances of the designed DFTC technique. Lower rotor flux and electromagnetic torque undulations and higher dynamic response are achieved by the designed DFTC technique. MATLAB software is used for numerical simulation.

\section{DFIG MODEL}

The DFIG is more famous in the field of electric power generation due to its characteristics. The mathematical form of this generator is based on the Park transformation. The latter is the most widely used in giving the sporty shape to electric machines. The following equations show the mathematical form of the DFIG [22]:

$$
\left\{\begin{array}{l}
V_{d r}=R_{r} I_{d r}-\omega_{r} \psi_{q r}+\frac{d}{d t} \psi_{d r} \\
V_{q r}=R_{r} I_{q r}+\omega_{r} \psi_{d r}+\frac{d}{d t} \psi_{q r} \\
V_{d s}=R_{s} I_{d s}-\omega_{s} \psi_{q s}+\frac{d}{d t} \psi_{d s} \\
V_{q s}=R_{s} I_{q s}+\omega_{s} \psi_{d s}+\frac{d}{d t} \psi_{q s}
\end{array}\right.
$$

The rotor and stator pulsations and rotor speed are interconnected by the following equation: $\omega_{s}=\omega_{r}+\omega$.

Where $\omega_{r}$ and $\omega_{s}$ are respectively the rotor and stator electrical pulsations, while $\omega$ is the mechanical one.

The rotor and stator flux can be written as follows:

$$
\left\{\begin{array}{l}
\Psi_{d r}=M I_{d s}+L_{r} I_{d r} \\
\psi_{q r}=M I_{q s}+L_{r} I_{q r} \\
\Psi_{d s}=M I_{d r}+L_{s} I_{d s} \\
\Psi_{q s}=M I_{q r}+L_{s} I_{q s}
\end{array}\right.
$$

$\left(V_{d r}, V_{q r}, V_{d s}, V_{q s}\right),\left(\psi_{d r}, \psi_{q r}, \psi_{d s}, \psi_{q s}\right),\left(I_{d r}, I_{q r}, I_{d s}, I_{q s}\right)$, are respectively the stator and rotor voltages, fluxes and currents, $R_{r}$ and $R_{s}$ are respectively the resistances of the stator and rotor windings, $L_{r}, L_{s}$, and $M$ are respectively the inductance own rotor, stator, and the mutual inductance between two coils.

The mechanical equation of the DFIG is:

$$
T_{e}=T_{r}+J \cdot \frac{d \Omega}{d t}+F_{r} \cdot \Omega
$$


The electromagnetic torque established by the DFIG can be written in terms of flux and currents by (4):

$$
T_{e}=\frac{3}{2} \frac{M}{L_{s}} n_{p}\left(-\psi_{d s} I_{q r}+\psi_{q s} I_{d r}\right)
$$

Where $J$ is the inertia, $\Omega$ is the mechanical rotor speed, $T_{r}$ is the load torque, and $F_{r}$ is the viscous friction coefficient.

The reactive and active powers of the stator side are defined as:

$$
\left\{\begin{array}{l}
Q_{s}=1.5\left(-V_{d s} I_{q s}+V_{q s} I_{d s}\right) \\
P_{s}=1.5\left(V_{q s} I_{q s}+V_{d s} I_{d s}\right)
\end{array}\right.
$$

In order to develop a decoupled control of the reactive and active powers, we use a Park reference frame linked to the stator flux. By supposing that the daxis oriented along the stator flux position and basing on equation (6) with neglecting Rs we can write [23]:

$$
\begin{aligned}
& \psi_{q s}=0 \text { and } \psi_{s}=\psi_{d s} \\
& \left\{\begin{array}{l}
V_{q s}=\psi_{s} \omega_{s} \\
V_{d s}=0
\end{array}\right. \\
& \left\{\begin{array}{l}
I_{q s}=-I_{q r} \frac{M}{L_{s}} \\
I_{d s}=\frac{\psi_{s}}{L_{s}}-I_{d r} \frac{M}{L_{s}}
\end{array}\right.
\end{aligned}
$$

Equation (8) can be written as:

$$
\left\{\begin{array}{l}
Q_{s}=-\frac{3}{2}\left(-\frac{\omega_{s} \psi_{s}^{2}}{L_{s}}+\frac{\omega_{s} \psi_{s} M}{L_{s}} I_{d r}\right) \\
P_{s}=(-1.5) I_{q r} \frac{\omega_{s} \psi_{s} M}{L_{s}}
\end{array}\right.
$$

Thus, the torque equation can be written as follows:

$$
T_{e}=-1.5 \frac{M}{L_{s}} n_{p} I q r^{\psi} d s
$$

\section{FRACTIONAL ORDER SUPER TWISTING ALGORITHMS}

Super twisting algorithms it is a type of nonlinear control. This type of controller is characterized by simplicity, durability and can be used in linear or non-linear systems. This type reduces the chattering phenomenon compared to the traditional sliding mode controller [24]. The STA controller has two parts. the first $\mathrm{u}_{1}$ is defined by its derivative with respect to time, while the second $\mathrm{u}_{2}$ is 
continuous and depends on the slip variable. The STA controller is one of the most widely used second-order sliding mode algorithms. This algorithm only applies to systems of relative degree 1. Its interest lies in the reduction of chattering, due to the continuity of the control signal. This control breaks down into an algebraic term and an integral term. we can therefore consider this algorithm as a nonlinear generalizer of a PI regulator.

Equation (11) represents STA controller [24].

$$
u(t)=u_{1}(t)+u_{2}(t)
$$

With:

$$
\begin{aligned}
& u_{1}(t)=\lambda_{1} \sqrt{|S|} \cdot \operatorname{sign}(S) \\
& u_{2}(t)=\lambda_{2} \int \operatorname{sign}(S) . d t
\end{aligned}
$$

The fractional calculus technique (FCT) is a generalization of the integration and ordinary differentiation to arbitrary non-integer order. Fractional calculus is an old mathematical method, but it provides very satisfactory results when used, and this is what we have noticed from the work done in this field. The idea of FCT has been a subject of interest not only among physicists but also among engineers and mathematicians. The FCTs are widely used in viscoelasticity, rheology, electromagnetism, electrochemistry, etc. [25]. In [26], fractional- order PI controllers were proposed to control the DFIG-based wind power. The results showed the effectiveness of the proposed method. A novel robust fractional-order sliding mode (FOSM) controller for maximum power point tracking control of DFIG-based wind energy conversion system [27]. In [28], a new method is proposed to control the active and reactive powers of DFIG using fractional-order sliding mode control (FOSMC) strategy. In [29], field-oriented control was proposed based on the fractional-order PI controllers to control the active and reactive power of DFIG.

In this section, a new controller has proposed: the Fractional Order Super Twisting Algorithm (FOSTA). We used the fractional calculus method to improve the performance and efficiency of the STA controller. The proposed FOSTA controller is a simple algorithm, more robust, and easy to adjust. Equation (14) represents the principle of the proposed FOSTA method.

$$
w(t)=\left(\lambda_{1} \sqrt{|S|} \cdot \operatorname{sign}(S)+\lambda_{2} \int \operatorname{sign}(S) \cdot d t\right)^{\alpha}
$$

where $\alpha$ is an adjustable parameter by which the performance and durability of the entire system can be greatly improved. If it is 1 , then a proposed FOSTA method becomes a classical STA controller.

This proposed FOSTA method will be used in this paper in order to improve the performance of the DFTC method and reduce both electromagnetic torque and rotor flux ripples of DFIG-based wind turbines. 


\section{DFTC METHOD WITH PI CONTROLLERS}

The classical DFTC technique is a famous technique in the AC machine control field. The main advantages of the classical DFTC technique are its simple algorithm, robust method, and its simple implementation. However, this method has some disadvantages, for example high torque and flux ripples. This strategy gives more harmonic distortion (THD) of current [30]. In [31], the author proposed the use of a DFIG with PI controllers (DFTC-PI) applied to DFIG-based wind power. In this DFTC-SVM or DFTC-PI control strategy, electromagnetic torque and rotor flux are regulated by two traditional PI regulators, while the SVM technique replaces the switching table. The DFTC-PI objective is to regulate the rotor flux and the electromagnetic torque of the DFIG-based wind turbine. The electromagnetic torque is regulated by means of the quadrature axis rotor voltage $V_{q r}$, while the rotor flux is regulated by means of the direct axis rotor voltage $V_{d r}$. The DFTC-PI technique, which is proposed to regulate electromagnetic torque and rotor flux of the DFIG-based wind turbine, is shown in Fig. 1. Through Fig. 1, we note that this method is very simple and the electromagnetic torque and rotor flux estimation block keep the same shape as that established for the classic DFTC technique.

This control by DPC-SVM, has the advantages of vector control and conventional DFTC technique to overcome the problem of fluctuations in torque and flux generated by DFIG. PI regulators and SVM techniques are used to achieve a fixed switching frequency and less electromagnetic torque and rotor flux pulses.

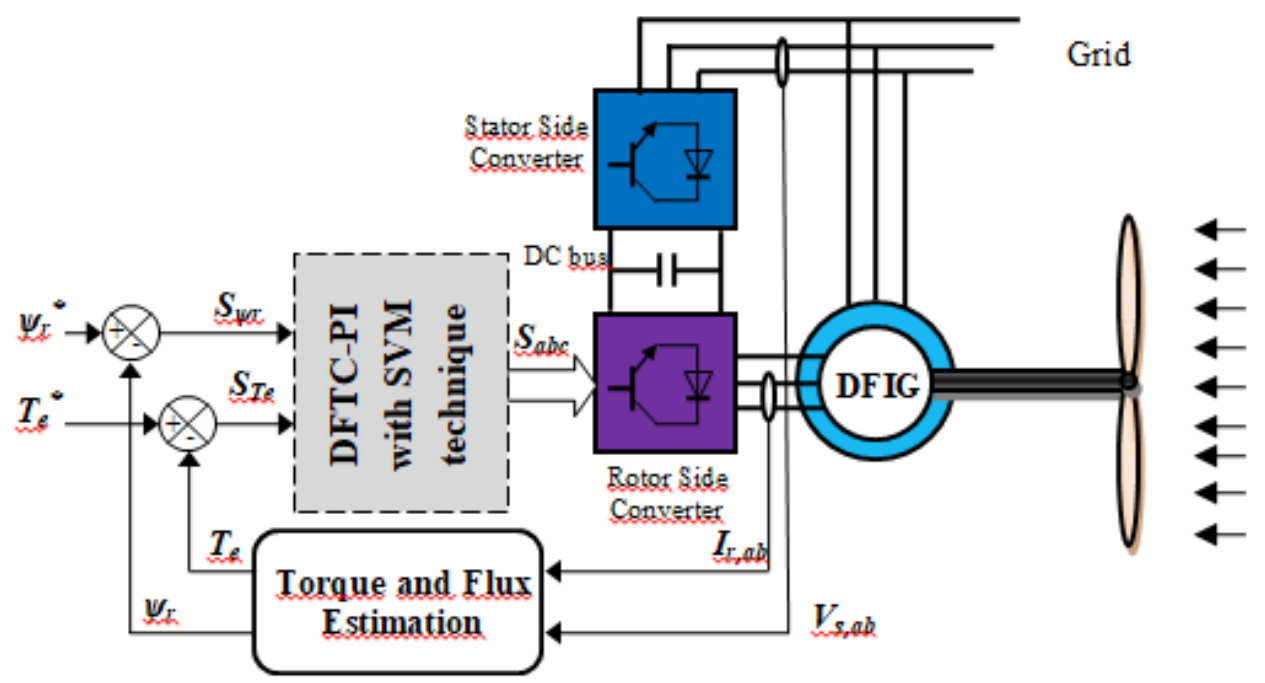

Fig. 1. Block diagram of the DFIG with DFTC-PI. 
The phase and amplitude of the rotor flux are estimated by the relation equations (15) to (16):

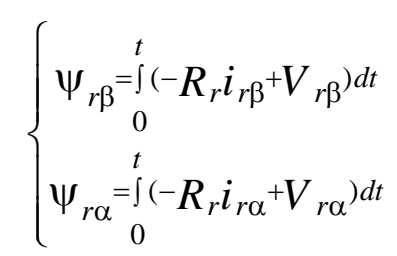

The magnitude and phase of rotor flux are described as follows:

$$
\begin{aligned}
\psi_{r} & =\sqrt{\psi_{r \alpha}^{2}+\psi_{r \beta}^{2}} \\
\theta_{r} & =\operatorname{arctg}\left(\frac{\psi_{r \beta}}{\psi_{r \alpha}}\right)
\end{aligned}
$$

With:

$$
\left|\overline{\psi_{S}}\right|=\frac{\left|\overline{V_{S}}\right|}{w_{S}}
$$

Consequently, the estimation of the rotor flux is based on the parameter of the rotor resistance.

The electromagnetic torque can be estimated from the measurement of the rotor current and the estimation of the stator flux.

$$
T_{e}=\frac{3}{2} \frac{M}{L_{s}} n_{p}\left(-\psi_{d s} I_{q r}+\psi_{q s} I_{d r}\right)
$$

On another side, the stator flux can be estimated from the measurement of the stator current and the stator voltage. Equation (20) shows the method of calculating the stator flux.

$$
\left\{\begin{array}{c}
\psi_{s \beta}=\int_{0}^{t}\left(-R_{s} i_{s \beta}+V_{s \beta}\right) d t \\
\psi_{s \alpha}^{t}=\int_{0}\left(-R_{s} i_{s \alpha}+V_{s \alpha}\right) d t \\
\psi_{0}
\end{array}\right.
$$

Equations (21) and (22) represent, magnitude and phase of stator flux respectively.

$$
\begin{aligned}
\psi_{s} & =\sqrt{\psi_{s \alpha}^{2}+\psi_{s \beta}^{2}} \\
\theta_{s} & =\operatorname{arctg}\left(\frac{\psi_{s \beta}}{\psi_{s \alpha}}\right)
\end{aligned}
$$

Due to the results obtained from this method compared to the classical DFTC method, but the problem of ripple remains at the level of electromagnetic 
torque and rotor flux. In the next section, we will try to propose a new DFTC method in order to reduce the electromagnetic torque and rotor flux ripples, as well as reduce the THD value of the stator current of DFIG.

\section{DFTC METHOD WITH FOSTA CONTROLLERS}

In order to improve the performance of the classic DFTC and DFTC-SVM techniques, the standard hysteresis comparators will be replaced by two FOSTA regulators and the switching table by the modified vector modulation technique (MSVM). The rotor flux and electromagnetic torque estimation block keep the same shape as that established for the conventional DFTC method. In this DFTC-FOSTA control strategy, the electromagnetic torque and the rotor flux are regulated by two FOSTA regulators. This proposed strategy is a more robust method, simple algorithm, easy to apply, and uncomplicated method compared to field-oriented control. The DFTC-FOSTA method, which is proposed to regulate electromagnetic torque and rotor flux of the DFIG-based wind turbine, is shown in Fig. 2. The DFTC-FOSTA objective is to regulate the rotor flux and the electromagnetic torque of the DFIG-based wind turbine. The electromagnetic torque is regulated by means of the quadrature axis rotor voltage $V_{q r}$, while the rotor flux is regulated by means of the direct axis rotor voltage $V_{d r}$. On the other hand, the DFTC control with proposed controllers minimized the electromagnetic ripple, current ripple, rotor ripple and THD value of current/voltage compared to classical DFTC and field-oriented control techniques.

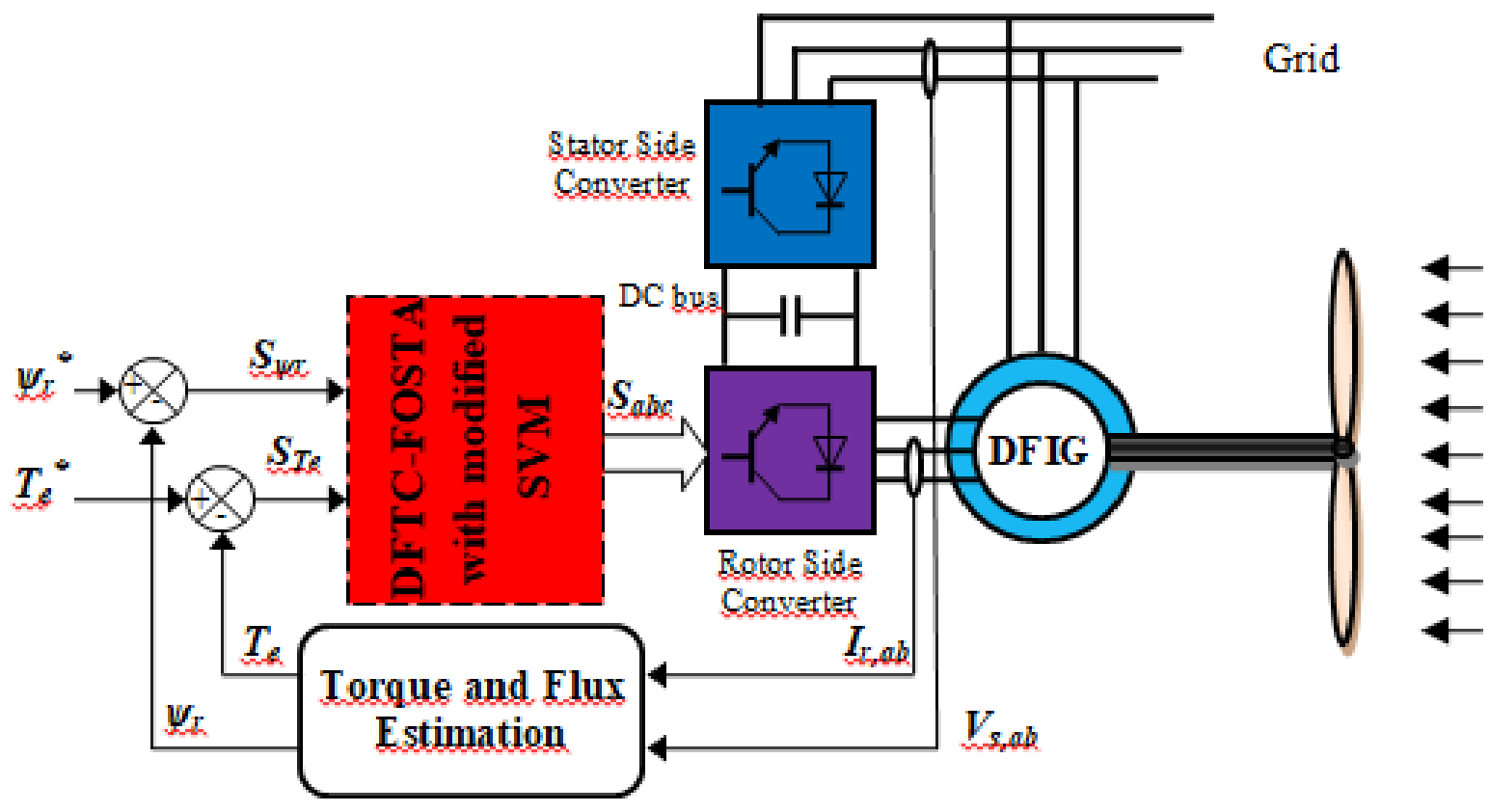

Fig. 2. Block diagram of the DFIG with DFTC-FOSTA. 
Electromagnetic torque and rotor flux FOSTA controllers are used to influence respectively the two rotor voltage components as in (23) and (24).

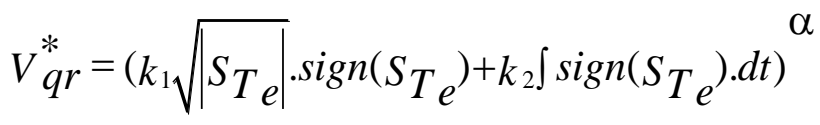

$$
\begin{aligned}
& V_{d r}^{*}=\left(k_{3} \sqrt{\left|S_{\psi_{r}}\right|} \cdot \operatorname{sign}\left(S_{\psi_{r}}\right)+k_{4} \int \operatorname{sign}\left(S_{\psi_{r}}\right) \cdot d t\right)^{\alpha}
\end{aligned}
$$

Where the sliding mode variables are the rotor flux magnitude error $S_{\psi r}=\psi_{r}{ }^{*}-\psi_{r}$ and the electromagnetic torque error $S_{T e}=T_{e}{ }^{*}-T_{e}$, and the control gains $K_{3}, K_{4}, K_{1}$ and $K_{2}$ should check the stability conditions.

The SVM technique is real-time modulation. it uses the fact that a vector can represent the three voltages of a three-phase zero-sum system. This modulation is used by modern controls of alternating current machines, the reference voltages are the desired voltages at the output of the inverter. The advantage of this technique is reducing the harmonic distortion compared to pulse width modulation (PWM). But this method is complicated, especially in the case of multilevel inverter and the cost becomes very high in this case. In [32], the author proposes a new SVM structure based on the calcule of minimum and maximum of three-phase voltages. This proposed SVM strategy is simple and easy to implement compared to the classical SVM technique [33]. The block diagram of the modified SVM technique is shown in Fig. 3.

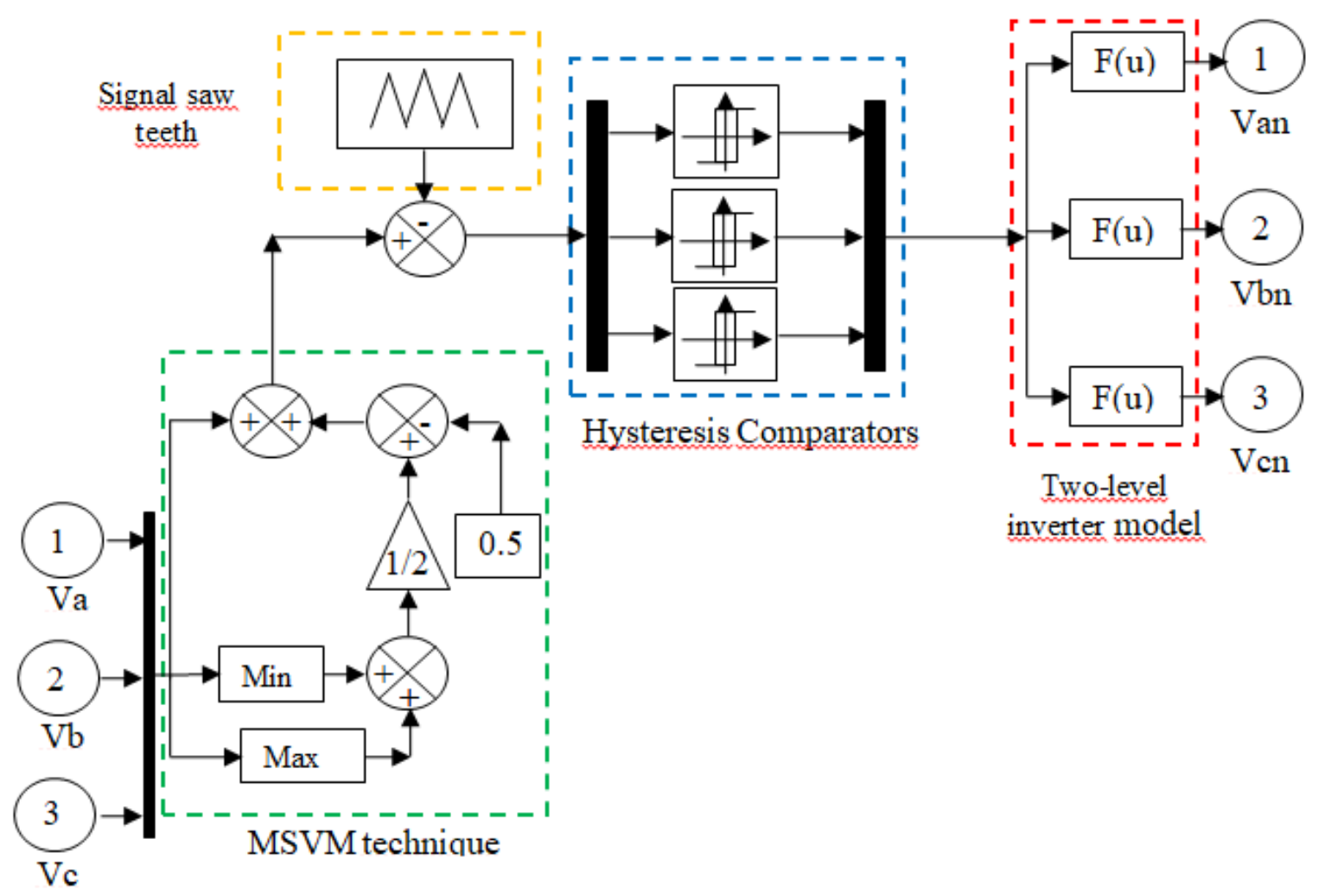

Fig. 3. Block diagram of the modified SVM technique 


\section{NUMERICAL SIMULATION}

In this section, numerical simulations are carried out with a $1.5 \mathrm{MW}$ DFIG attached to a $398 \mathrm{~V} / 50 \mathrm{~Hz}$ grid, by using the MATLAB software. The two DFTC methods; DFTC-PI and DFTC-FOSTA technique are simulated and compared in terms of robustness against machine parameter variations, stator current harmonics distortion, and reference tracking.

The DFIG used in our work has the following parameters [32, 33]:

$$
\begin{aligned}
& P_{n}=1.5 \mathrm{MW} \\
& p=2 \\
& R_{s}=0.012 \Omega, 50 \mathrm{~Hz}, 380 / 696 \mathrm{~V} \\
& R_{r}=0.021 \Omega \\
& L_{s}=0.0137 \mathrm{H} \\
& J=1000 \mathrm{~kg} \times \mathrm{m}^{2} \\
& f_{r}=0.0024 \mathrm{Nm} / \mathrm{s} \\
& L_{r}=0.0136 \mathrm{H} \\
& L_{m}=0.0135 \mathrm{H}
\end{aligned}
$$

\subsection{Reference tracking test}

In this case, the effectiveness and performance of the DFTC-FOSTA and DFTC-PI control are tested under reference electromagnetic torque and rotor flux variation. The reference values of electromagnetic torque and rotor flux are set at $3500 \mathrm{~N} \times \mathrm{m}$ and $1 \mathrm{wb}$, respectively. Fig. 4-11 show the obtained simulation results from this test. The waveforms are taken from 0 to $0.4 \mathrm{sec}$ for better illustrations. From Fig. 7, 8, we notice that the electromagnetic torque and rotor flux follow the references precisely. On the other hand, the proposed technique reduced the torque and flux ripples compared to the DFTC-PI technique (Fig. 10,11). It is shown that the FOSTA controller has high effectiveness compared to the traditional PI controller.

Fig. 6 represents the current signal for both DFTC methods. Starting from Fig. 6, we notice that the stator current is related to the system, as well as the reference values of electromagnetic torque and rotor flux. From Fig. 9, we notice that the proposed DFTC method greatly reduced the ripple of stator current of the DFIG compared to DFTC-PI. On the other hand, Fig. 4, 5 show the THD of current (Ias) of the DFIG for the designed and classical DFTC methods. It can be clearly observed through these Figures that the THD value is more reduced for the DFTC-FOSTA $(0.16 \%)$ when compared to the DFTC-PI $(0.63 \%)$. Based on the obtained results, it can be said that DFTC-FOSTA has proven effective in reducing the value of undulations both in stator current and electromagnetic torque. 

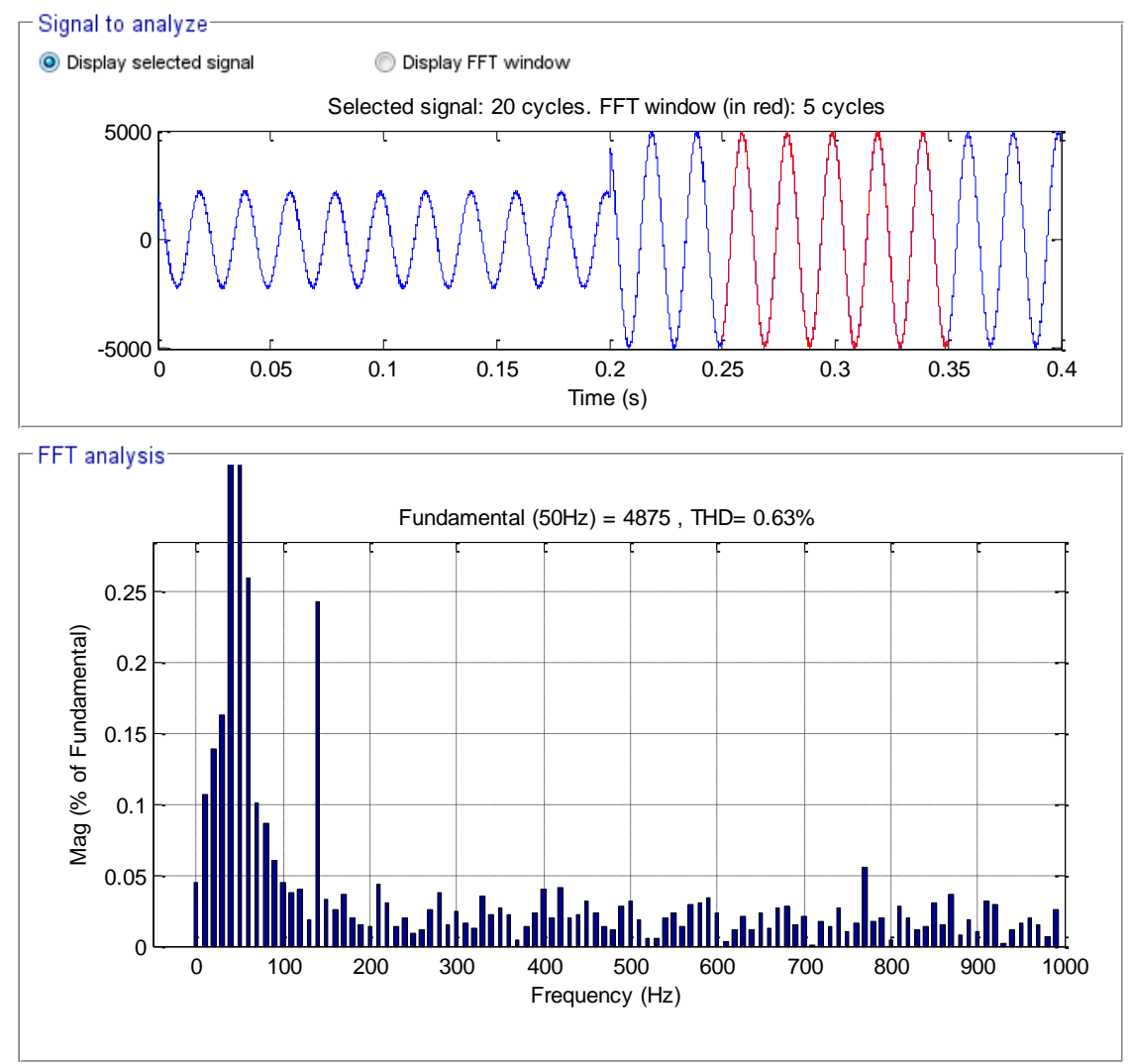

Fig. 4. THD (DFTC-PI)
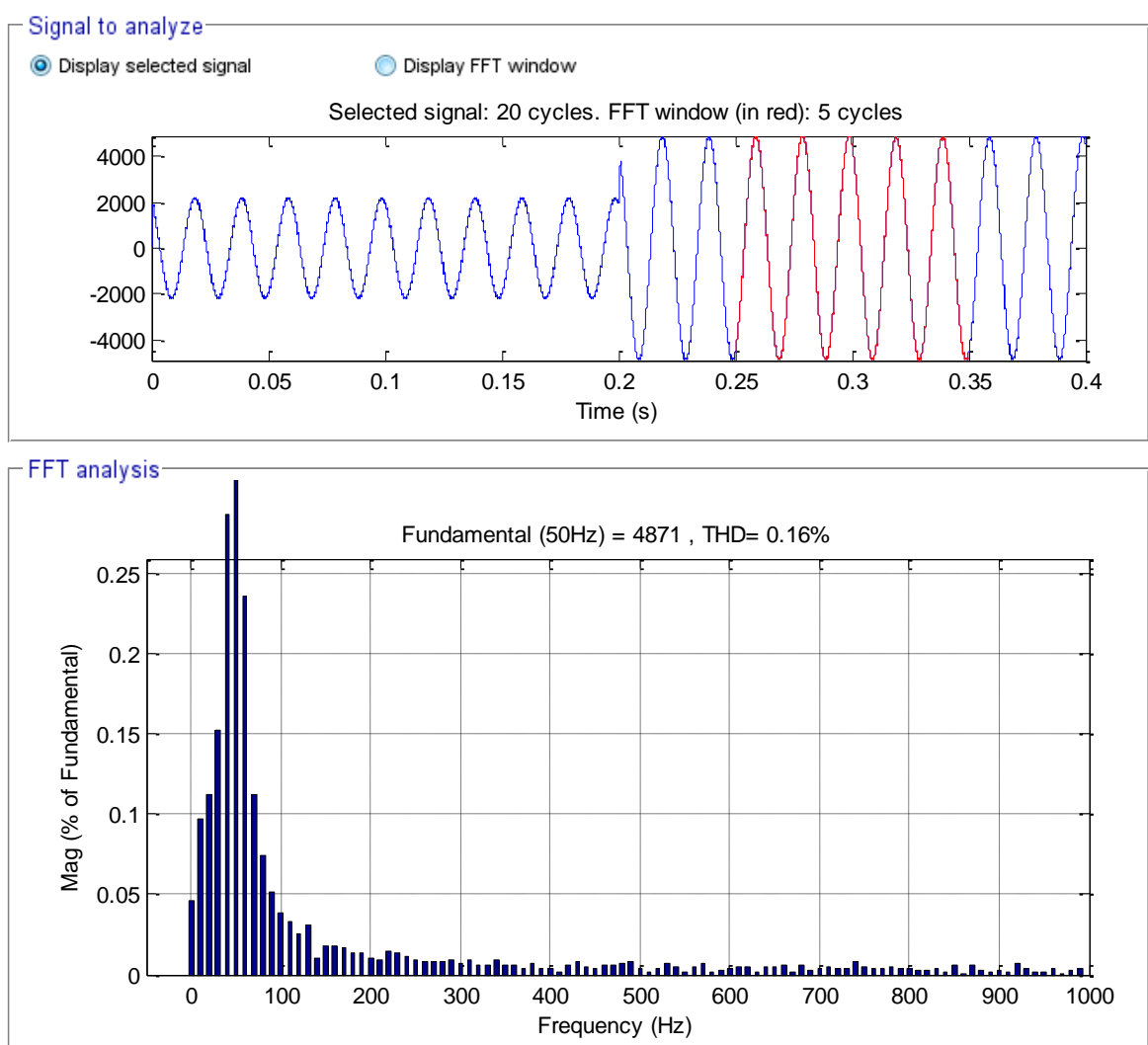

Fig. 5. THD (DFTC-FOSTA) 


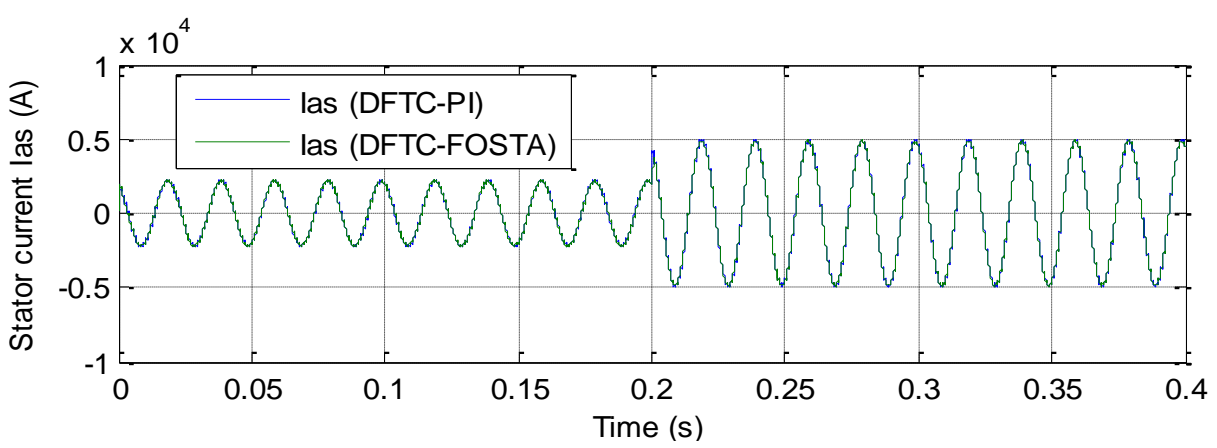

Fig. 6. Stator current

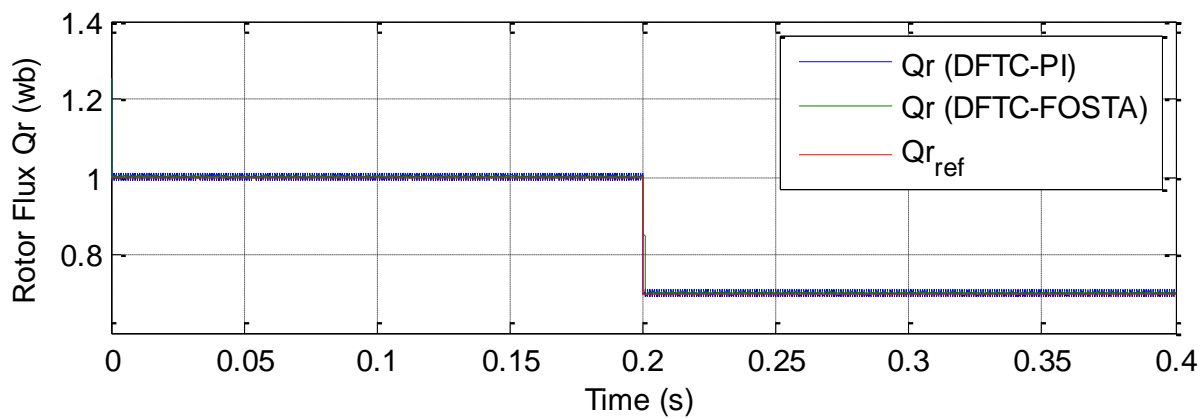

Fig. 7. Rotor flux

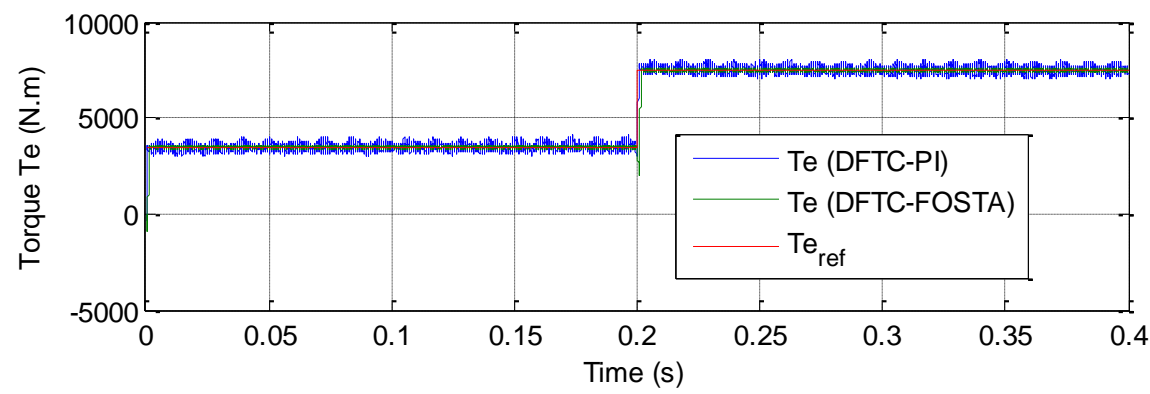

Fig. 8. Torque

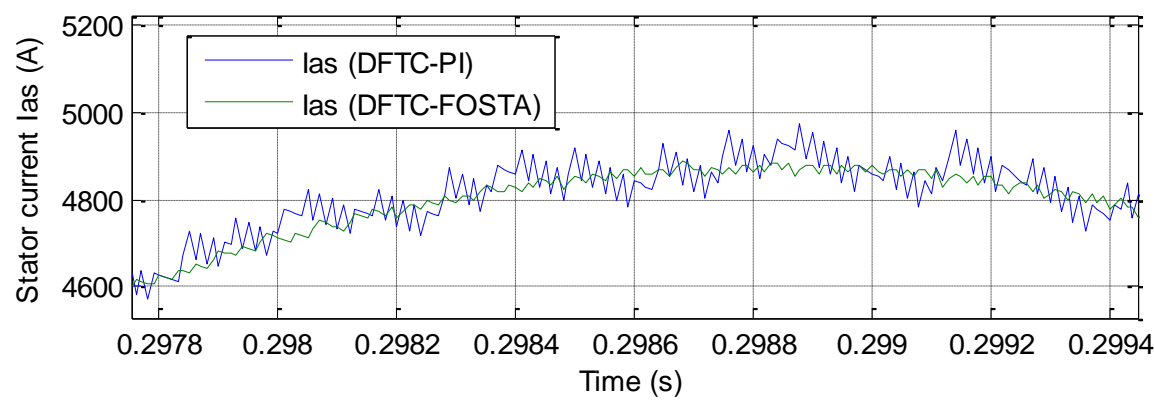

Fig. 9. Zoom (Current Ias)

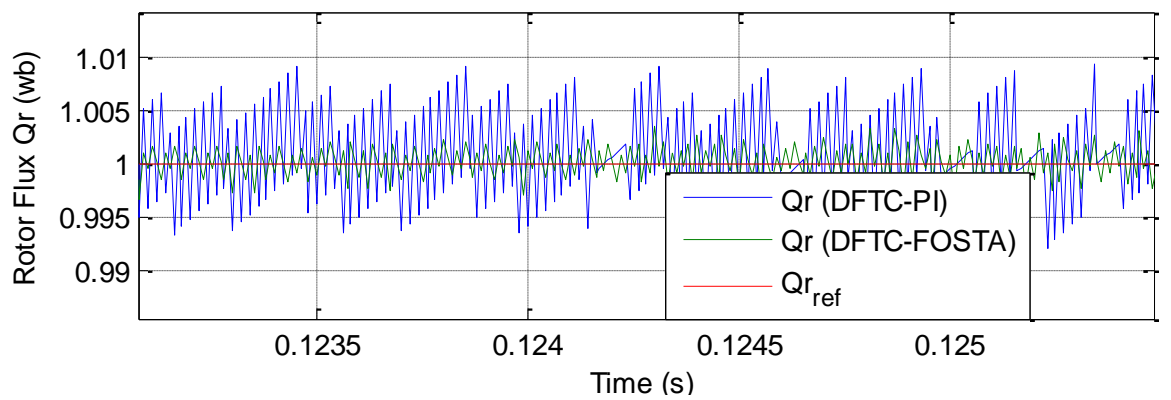

Fig. 10. Zoom (Rotor flux) 


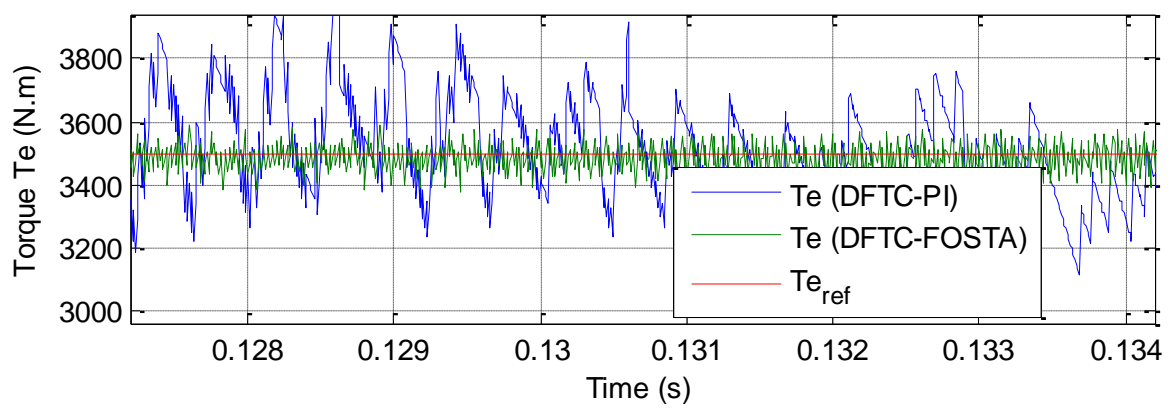

Fig. 11. Zoom (Torque)

\subsection{Robustness test}

In order to examine the robustness of the DFTC-FOSTA technique, the nominal value of the values of inductances $L_{s}, M$, and $L r$ are multiplied by 0.5 and the $R_{r}$ and $R_{s}$ are multiplied by 2 . Simulation results are presented in Fig. 12-19. As it's shown by these Figures, these variations present a clear effect on the stator current, rotor flux, and electromagnetic torque curves (Fig. 15-17) and that the effect appears more important for the DFTC-PI control method compared to the DFTC-FOSTA technique (Fig. 18-19). On the other hand, the THD value of stator current in the DFTC-FOSTA method has been minimized significantly (Table). Thus, it can be concluded that the designed DFTC-FOSTA technique is more robust than the DFTC-PI control method.

Table. Comparative analysis of THD value

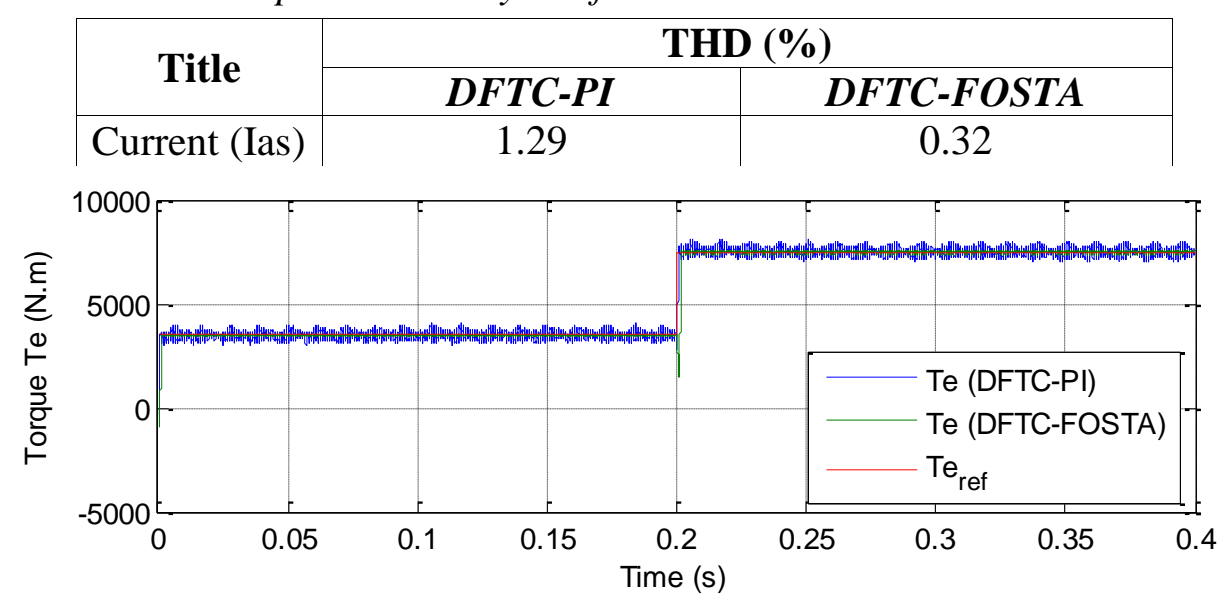

Fig. 12. Torque

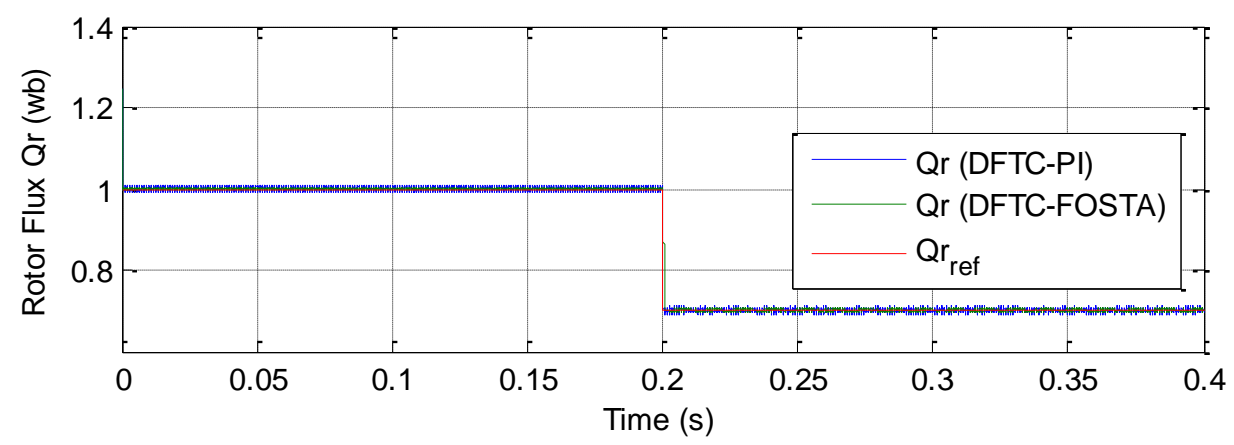

Fig. 13. Rotor flux 


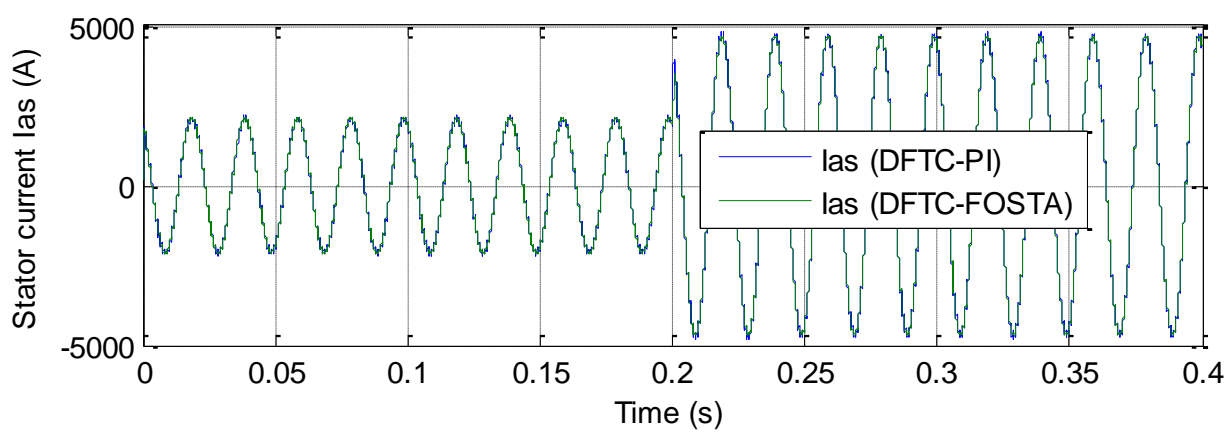

Fig. 14. Stator current

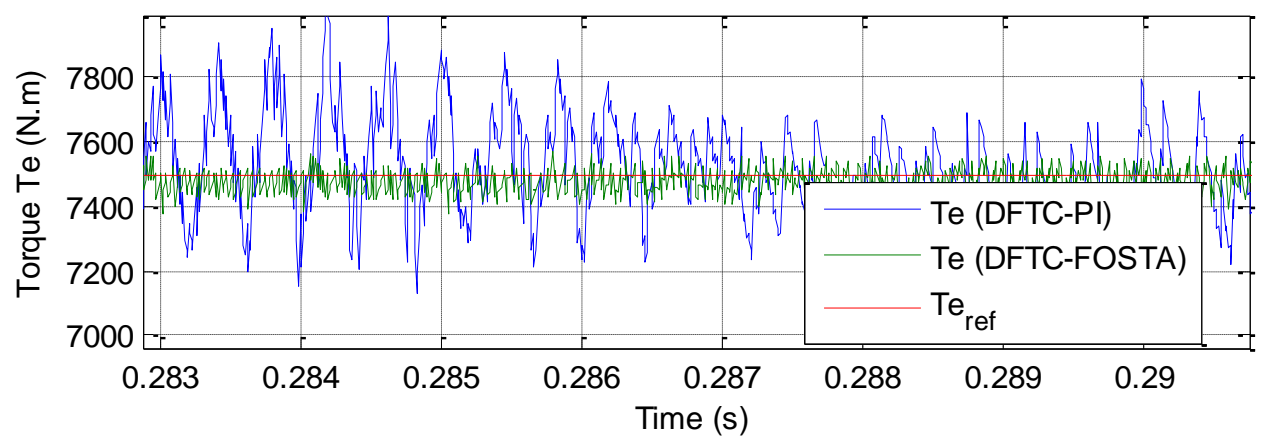

Fig. 15. Zoom (Torque)

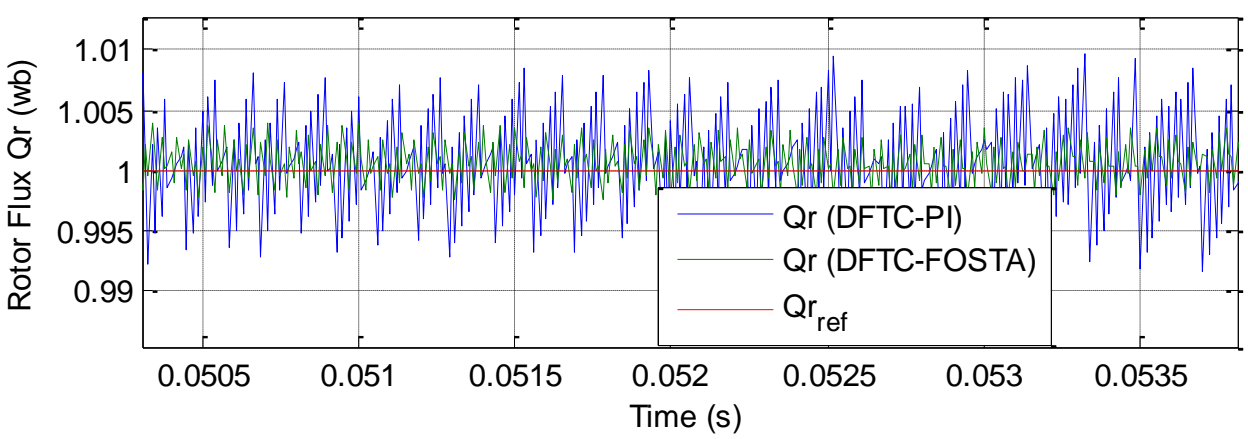

Fig. 16. Zoom (Rotor flux)

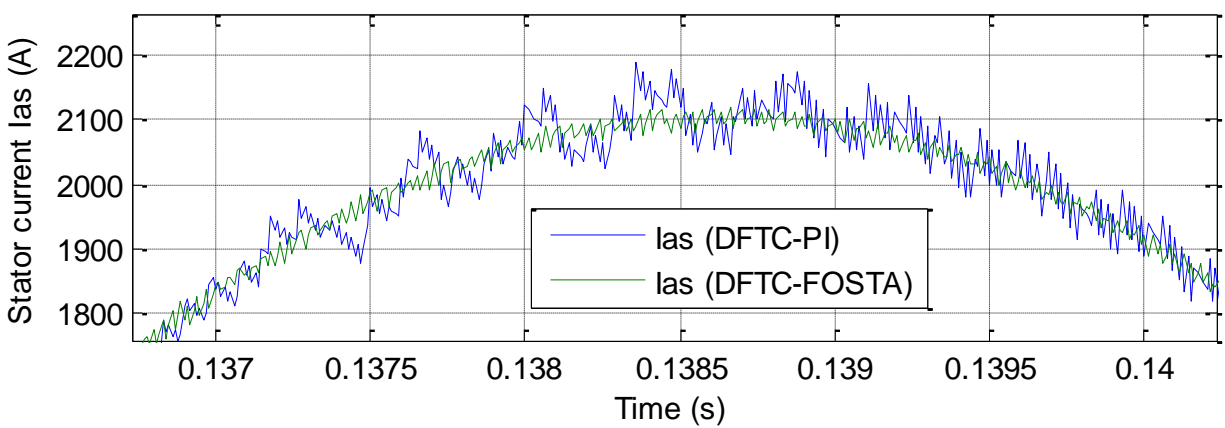

Fig. 17. Zoom (Stator current) 

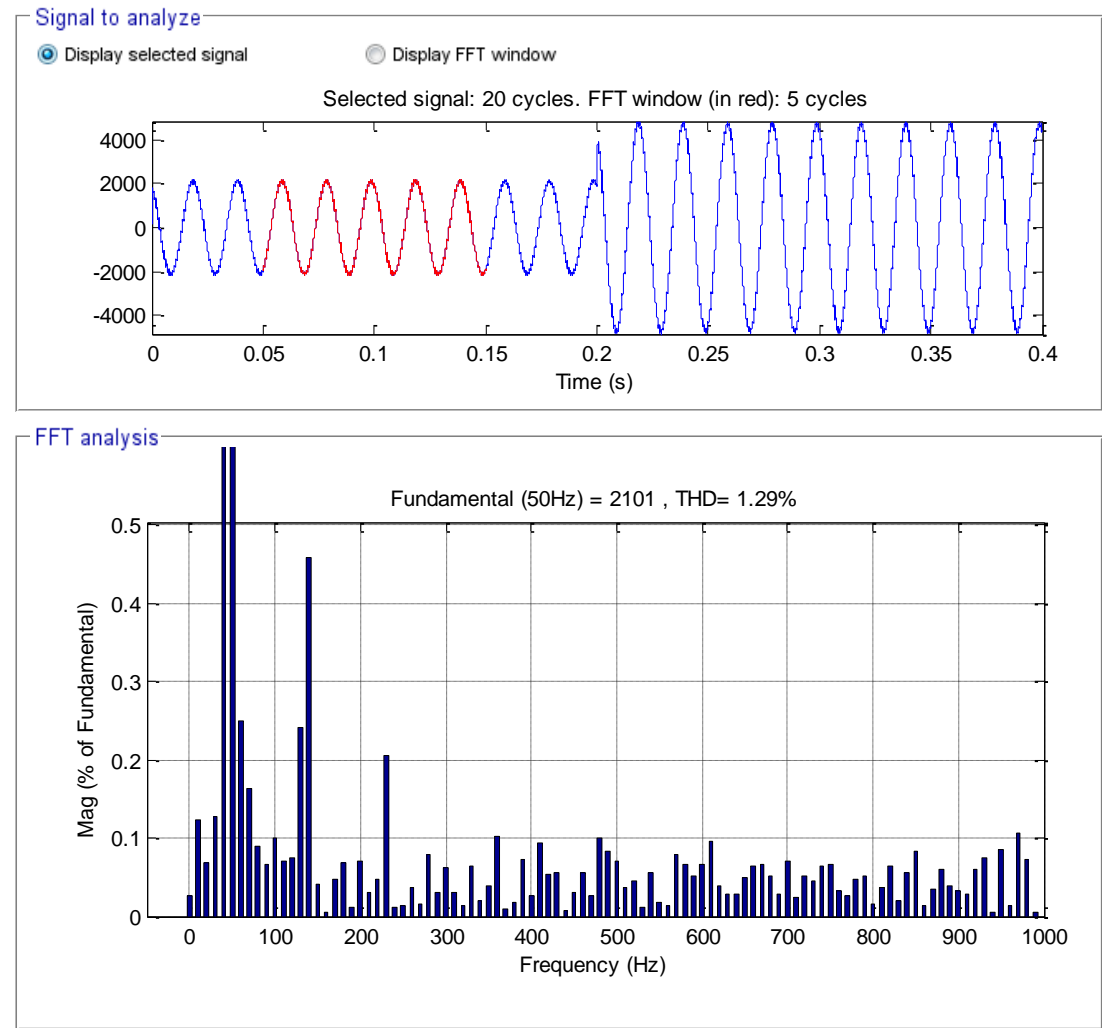

Fig. 18. THD (DFTC-PI)
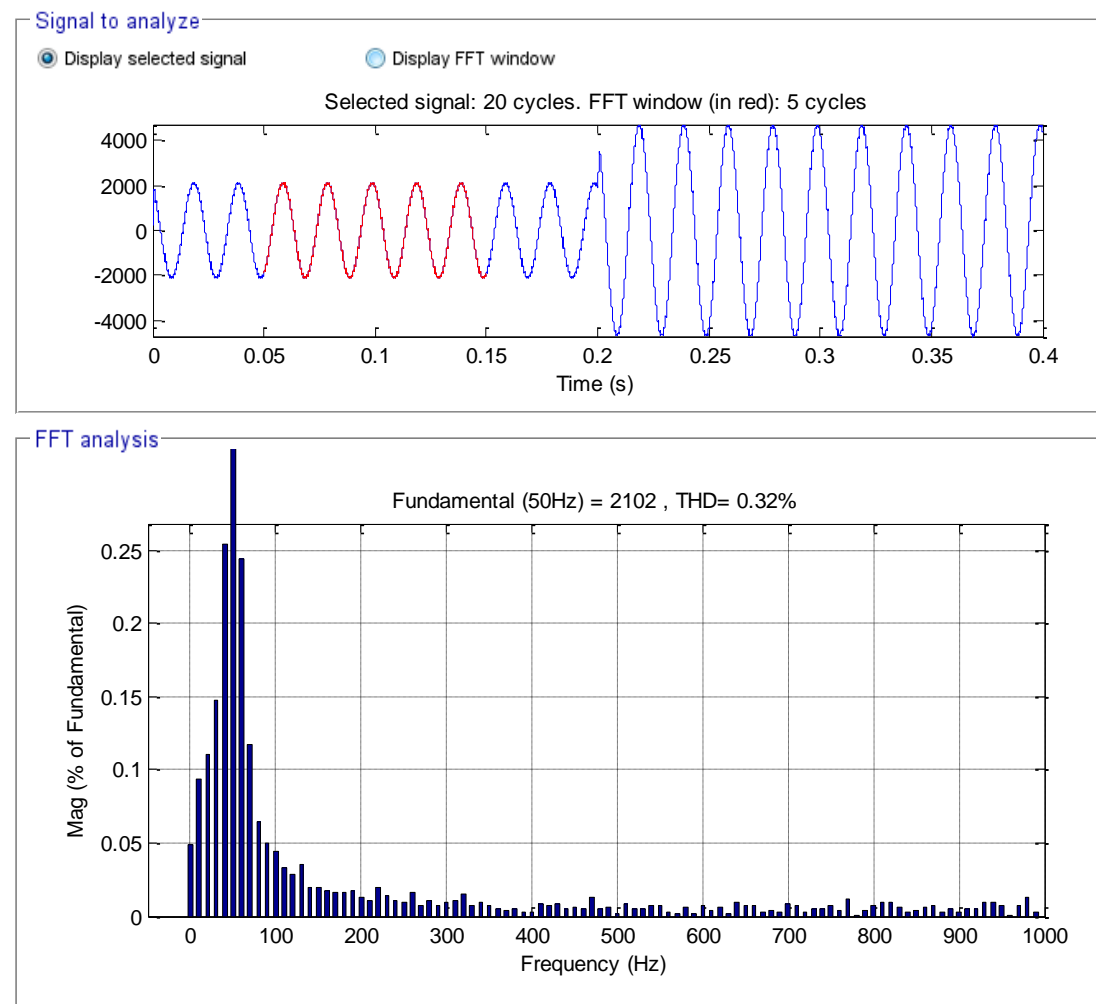

Fig. 19. THD (DFTC-FOSTA) 


\section{CONCLUSION}

This work presents the simulation results of the rotor flux and electromagnetic torque fractional-order super twisting control technique of a DFIG-based wind turbine, using the modified SVM technique. With results obtained from the numerical simulation, it is clear that for the same operation condition, the DFTC control with FOSTA controllers had high effectiveness and performance than the DFTC control using traditional PI controllers and that is clear in the THD value of stator current which the use of the FOSTA controller, it is reduced of harmonics more than the PI controller.

\section{The authors make it expressly clear that:}

1. No conflict of interests has taken or make take place;

2. The present article does not contain any researches with people involved as the objects of researches.

\section{References}

1. Liu D, Polinder H, Abrahamsen AB, Ferreira JA. Effects of armature winding segmentation with multiple converters on the short circuit torque of 10-MW superconducting wind turbine generators. IEEE Transactions on Applied Superconductivity. 2017; 27(4):1-5. doi: 10.1109/TASC.2016.2639029

2. Djeriri Y. Lyapunov-based robust power controllers for a doubly fed induction generator. Iranian Journal of Electrical and Electronic Engineering. 2020; 16(4):551558. doi: 10.22068/IJEEE.16.4.551

3. Prasad R, Padhy NP. Synergistic frequency regulation control mechanism for DFIG wind turbines with optimal pitch dynamics. IEEE Transactions on Power Systems. 2020; 35(4):3181-3191. doi: 10.1109/TPWRS.2020.2967468

4. Mondal S, Kastha D. Input reactive power controller with a novel active damping strategy for a matrix converter fed direct torque controlled DFIG for wind power generation. IEEE Journal of Emerging and Selected Topics in Power Electronics. 2020; 8(4):3700-3711. doi: 10.1109/JESTPE.2019.2938012

5. Yu SS, Zhang G, Fernando T, Iu HH. A DSE-Based SMC method of sensorless DFIG wind turbines connected to power grids for energy extraction and power quality enhancement. IEEE Access, 2018;6:76596-76605. doi: 10.1109/ACCESS.2018.2883591

6. Benbouhenni H, Boudjema Z, Belaidi A. DPC based on ANFIS super-twisting sliding mode algorithm of a doubly-fed induction generator for wind energy system. Journal Européen des Systèmes Automatisés, 2020;53(1):69-80.

7. Prasad RM, Mulla MA. A novel position-sensorless algorithm for field-oriented control of DFIG with reduced current sensors. IEEE Transactions on Sustainable Energy. 2019;10(3):1098-1108. doi: 10.1109/TSTE.2018.2860993

8. Mondal S, Kastha D. Improved direct torque and reactive power control of a matrixconverter-fed grid-connected doubly fed induction generator. IEEE Transactions on Industrial Electronics, 2015;62(12):7590-7598. doi: 10.1109/TIE.2015.2459056

9. Zhang Z, Tang R, Bai B, Xie D. Novel direct torque control based on space vector modulation with adaptive stator flux observer for induction motors. 
IEEE Transactions on Magnetics. 2010;46(8):3133-3136. doi: 10.1109/TMAG.2010.2051142

10. Benbouhenni H. Four-level direct torque control of permanent magnet synchronous motor based on neural networks with regulation speed using neural PI controller. Majlesi Journal of Mechatronic Systems, 2019;8(4):1-10.

11. Benbouhenni H, Boudjema Z. Two-level DTC based on ANN controller of DFIG using 7-level hysteresis command to reduce flux ripple comparing with traditional command. 2018 International Conference on Applied Smart Systems (ICASS). November 24-25. Medea, Algeria. 2018. doi: 10.1109/ICASS.2018.8652013

12. Zhang Z, Zhao Y, Qiao W, Qu L. A discrete-time direct torque control for directdrive PMSG-based wind energy conversion systems. IEEE Transactions on Industry Applications. 2015;51(4):3504-3514. doi: 10.1109/TIA.2015.2413760

13. El Ouanjli N, Motahhir S, Derouich A, El Ghzizal A, Chebabhi A, Taoussi M. Improved DTC strategy of doubly fed induction motor using fuzzy logic controller. Energy Reports. 2019;5:271-279. doi: 10.1016/j.egyr.2019.02.001

14. Benbouhenni H. Torque ripple reduction of DTC DFIG drive using neural PI regulators. Majlesi Journal of Energy Management. 2019;8(2):21-26.

15. Arbi J, Ghorbal MJ, Slama-Belkhodja I, Charaabi L. Direct virtual torque control for doubly fed induction generator grid connection. IEEE Transactions on Industrial Electronics. 2009;56(10):4163-4173. doi: 10.1109/TIE.2009.2021590

16. Giribabu D, Kumar A. Comparative study of control strategies for the induction generators in wind energy conversion system. Wind and Structures.2016;22(6):635662. doi: 10.12989/was.2016.22.6-.635

17. Boudjema Z, Taleb R, Djerriri Y, Yahdou A. A novel direct torque control using second order continuous sliding mode of a doubly fed induction generator for a wind energy conversion system. Turkish Journal of Electrical Engineering \& Computer Sciences. 2017;25(2): 965-975.

18. Farid B, Tarek B, Sebti B. Fuzzy super twisting algorithm dual direct torque control of doubly fed induction machine. International Journal of Electrical and Computer Engineering. 2021;11(5). doi: 10.11591/ijece.v11i5.pp\%25p

19. Benbouhenni $H$. Utilization of an ANFIS-STSM algorithm to minimize total harmonic distortion. International Journal of Smart Grid. 2020;4(2):56-67.

20. Benbouhenni H. Stator current and rotor flux ripples reduction of DTC DFIG drive using FSTSMC algorithm. International Journal of Smart Grid. 2019;3(4).

21. Benbouhenni H. Rotor flux and torque ripples minimization for direct torque control of DFIG by NSTSM algorithm. Majlesi Journal of Energy Management. 2018;7(3).

22. Amrane F, Chaiba A. A novel direct power control for grid-connected doubly fed induction generator based on hybrid artificial intelligent control with space vector modulation. Rev. Sci. Techni.-Electrotechn. Et Energ. 2016;61(3):263-268.

23. Tavakoli SM, Pourmina MA, Zolghadri MR. Comparison between different DPC methods applied to DFIG wind turbines. International Journal of Renewable Energy Research. 2013;3(2):446-452.

24. Listwan J. Application of super-twisting sliding mode controllers in direct fieldoriented control system of six-phase induction motor: experimental studies. Power Electronics and Drives. 2018;3(1):23-34. doi: 10.2478/pead-2018-0013.

25. Nieto JJ. Maximum principles for fractional differential equations derived from mittag-leffler functions. Applied Mathematics Letters. 2010;23(10):1248-1251. doi: 10.1016/j.aml.2010.06.007

26. Chen H, Wei X, Chen X, Jingang H, Aït-Ahmed N, Zhibin Z, Tianhao T, Mohamed 
B. Fractional-Order PI Control of DFIG-Based Tidal Stream Turbine. J. Mar. Sci. Eng. 2020;8(5)1-23. doi: 10.-3390/jmse8050309

27. Ebrahimkhani S. Robust fractional order sliding mode control of doubly-fed induction generator (DFIG)-based wind turbines. ISA Transactions, 2016;63:343-354. doi: 10.1016/j.isatra.2016.0-3.003

28. Xiong L, Wang J, Mi X, Khan MW. Fractional order sliding mode based direct power control of grid-connected DFIG. IEEE Transactions on Power Systems. 2018;33(3):3087-3096. doi: 10.1109/TPWRS.201-7.2761815

29. Azza A, Kherfane H. Robust control of doubly fed induction generator using fractional order control. International Journal of Power Electronics and Drive System. 2018;9(3):1072-1080. doi: 10.11591/ij-peds.v9.i3.pp1072-1080

30. Kashkooli MRA, Madani SM, Lipo TA. Improved Direct Torque Control for a DFIG under Symmetrical Voltage Dip With Transient Flux Damping. IEEE Transactions on Industrial Electronics. 2020;67(1):28-37. doi: 10.1109/TIE.2019.2893856

31. Cherifi D. Improvement technique of direct torque control of DFIG based in wind energy conversion system. Global Journal of Information Technology: Emerging Technologies. 2020;10(1):22-34. doi: 10.18844/gjit.v10i1.4630

32. Benbouhenni H, Boudjema Z, Belaidi A. Power Control of DFIG in WECS Using DPC and NDPC-NPWM Methods. Mathematical Modelling of Engineering Problems. 2020;7(2):223-236.

33. Benbouhenni H, Boudjema Z, Belaidi A. Direct power control with NSTSM algorithm for DFIG using SVPWM technique. Iranian Journal of Electrical \& Electronic Engineering. 2021;17(1):1-11.

\section{Information about the authors:}

Almakki Ali Nadhim Jbarah, Postgraduate;

ORCID: 0000-0002-0061-6425;

E-mail: alinadhimj@gmail.com

Mazalov Andrey, $\mathrm{PhD}$, associate professor;

eLibrary SPIN: 6534-7455; ORCID: 0000-0003-3761-0059; Scopus ID: 55927486000;

E-mail: anmaz8@list.ru

\section{To cite this article:}

Almakki ANJ, Mazalov AA. Improved DFIG DFTC by using a fractional-order super twisting algorithms in wind power applications. Modern Transportation Systems and Technologies. 2021;7(3):131-149. doi: 10.17816/transsyst202173131-149 